\title{
Adolescent Decision-Making Capacity: Special Considerations in Evaluation from Neurobiological, Ethical and Legal Perspectives
}

\author{
Leigh Goodrich, MD \\ University of California, Irvine Department of Psychiatry \& Human Behavior
}

\section{Overview:}

Advancements in developmental neurobiology have increasingly informed how the American judicial system considers matters pertaining to adolescents. This research informs clinical evaluations of medical decision-making capacity in this specific population.

Reviewing case law reveals how judicial decisions regarding adolescent minors have increasingly considered the importance of structural and functional differences between adolescent and adult brains. In this way, research supporting the vulnerability of adolescent neurobiology when it comes to executive functioning, impulse control and emotional regulation stands in contrast to advocacy efforts to support the rights of self-determination and "mature minor" standards for decision-making and autonomy.

\section{Neurobiological Changes in Adolescence:}
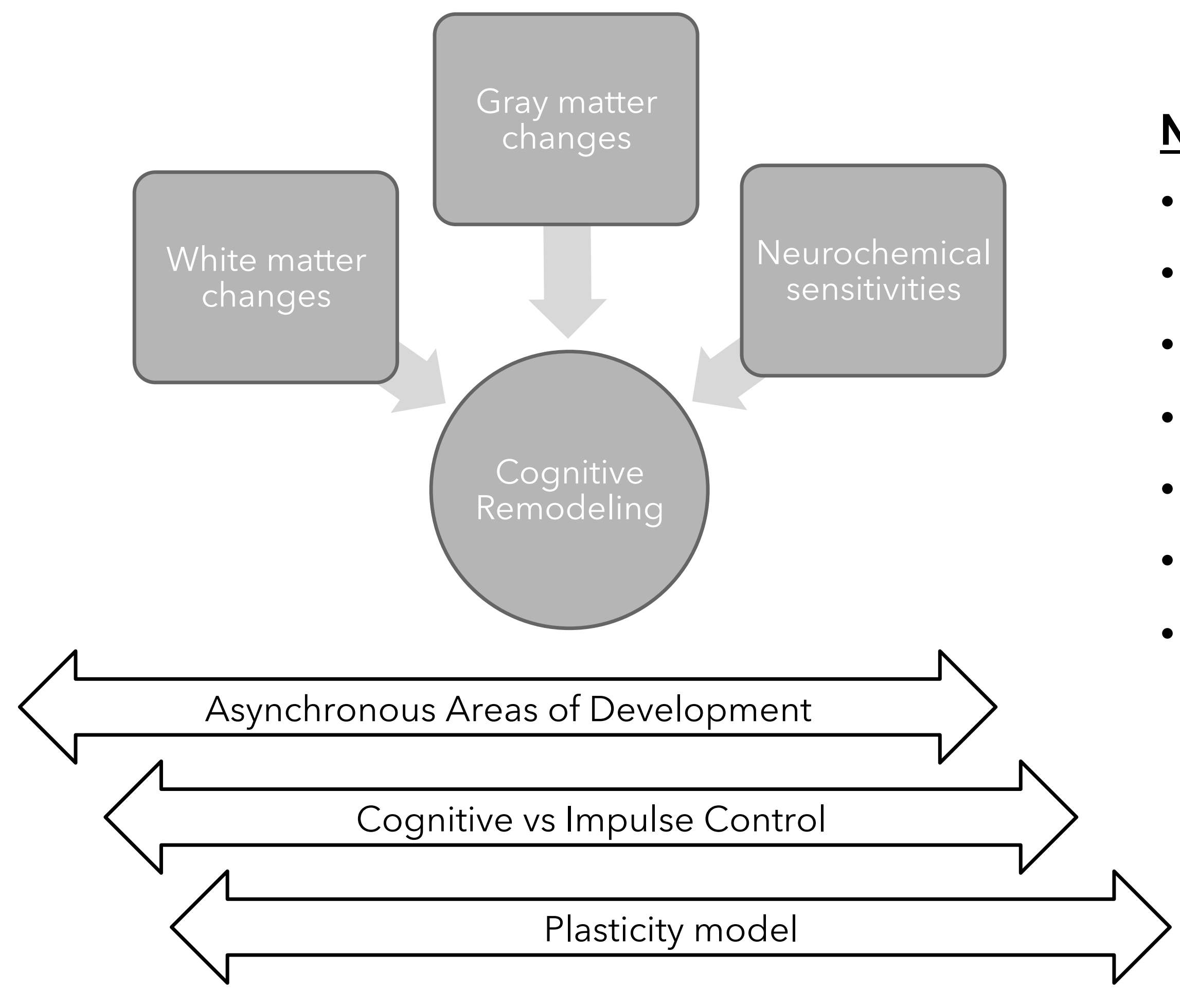

\section{Notable Case Law to Discuss:}

- Roper v. Simmons

- Miller v. Alabama

- In re. Cassandra C.

- Graham v. Florida

- Bakker v. Welsh

- Browning Principle

- Cardwell v. Bechtol

\section{United Nations Convention on the Rights of the Child: Key Principles}

- Article 5: we "shall respect the responsibilities, rights and duties of parents [or persons legally responsible for the child]..."in a manner consistent with the evolving capacities of the child".

- Article 12: child "who is capable of forming his or her own views [has] the right to express those views freely in all matters affecting the child," with "the views of the child being given due weight in accordance with the age and maturity of the child."

- Article 13: "right to freedom of expression"; "freedom to seek, receive and impart information and ideas of all kinds"

- Article 24: "right of the child to the enjoyment of the highest attainable standard of health and to facilities for the treatment of illness and rehabilitation of health" 